\title{
ПЕДАГОГИЧЕСКИЙ ПРАКТИКУМ
}

\author{
Лилия Шумская
}

DOI: 10.37492/ETN0.2021.66.4.013

\section{Восприятие русской народной сказки при изучении РКИ}

В статье рассматривается механизм взаимодействия разных социальных групп, взаимопонимание культур которых обусловливает способность к межкультурному общению и формирует социокультурную компетенцию в процессе овладения русским языком как иностранным. Выявляются проблемы восприятия и декодирования фольклорного текста, анализируются возникающие образно-понятийные и культурологические затруднения. Прослеживаются различия в восприятии и оценке культурно значимых фольклорных мотивов реципиентами разных ментальностей. Отмечается, что изучение народных сказок способствует формированию представления о ценностях, культуре, составляющих своеобразие менталитета русского народа.

Ключевые слова: диалог культур, коммуникация, сказка, фольклор, ченности, традиции, соразвитие, русский как иностранный (РКИ).

\section{Шумская Лилия Михайловна,}

кандидат филологических наук, дочент кафедры языковой подготовки белорусских и иностранных граждан, Гродненский государственный университет имени Янки Купалы (Гродно, Республика Беларусь),akay2012@yandex.ru
В современной педагогике особое значение приобретает исследование природы межчеловеческих связей и механизма взаимодействия коллективных субъектов, представленных разными историческими и культурными социальными группами. Взаимопонимание культур обусловливает способность к межкультурному общению и формирует социокультурную компетенцию как конечный результат овладения языком [3]. В эпоху глобализации открываются новые возможности в решении актуальных задач постижения культурных ценностей других народов, приобщения иноязычных обучающихся к различным формам наци- 
ональной культуры, способствующим формированию их социокультурной компетенции.

С нашей точки зрения принципиально важно осуществлять процесс обучения РКИ в диалоге иностранной и родной культур. Это оказывается возможным при изучении фольклорного произведения - сказки. Через сказку и ее восприятие осуществляется трансляция опыта людей, их межкультурный диалог, направленный на сближение.

В возможности диалога культур убеждают следующие предпосылки. Во-первых, взаимопроникновение субъектов - носителей разных ценностей. Лингвистическая общность людей на основе английского языка пересекается с целым рядом самостоятельных государственных образований - Великобританией, США, Канадой, Австралией, Новой Зеландией. Одного вероисповедания могут придерживаться представители разных этносов и этнических групп - католиком является и испанец, и поляк, и бразилец. В то же время представители одного этноса нередко принадлежат к разным конфессиям - среди белорусов есть и православные, и католики. Пересекаются между собой также классовые, национальные и профессиональные страты. Во-вторых, субъекты, принадлежащие к разным культурам, имеют сходные ценности. Так, материнство, мужественность и человеческое достоинство высоко ценятся в самых разных культурах. В.А. Лекторский справедливо констатирует: «В действительности каждая культура, ценностная и познавательная система не только вступает в борьбу с другой системой, но так или иначе пытается учесть опыт другой системы, расширяя тем самым горизонт своего собственного опыта» [4, с. 15].

Однако проблема состоит в том, что для большинства инофонов речевое общение на иностранном языке предполагает затрудненное восприятие не буквальных, 
а имплицитных смыслов, иностранный язык является для них ценностью потенциальной, а не реальной, что осложняет полноценное коммуникативное общение.

Взаимодействие ценностно-мировоззренческих систем и диалог культур в условиях овладения русским языком как иностранным делают чрезвычайно актуальной задачу определения социального пространства для тех или иных ценностей. Механический перенос ценностей в инородную культурную среду чреват конфликтами, апелляция к ценностному ряду локального общества в прямых контактами между людьми может встретить агрессивное неприятие.

В сказках содержится существенный лингвокультурологический материал, скрытый от инокультурного читателя. Именно в этом жанре фольклора проявляется национальная психология, утверждаются традиционные нравственные идеалы, формы поведения и способы коммуникации представителей определенной этнокультурной среды. Национальный колорит сказок, непонятный инофонам, выражается в специфических сюжетах, оценке происходящих событий, образах, именах героев, традиционных языковых формулах: Дед Мороз, сестрица, братец, старичок, добрый молодец, красна девица - краса ненаглядная. Но особенно трудными для восприятия оказываются действия сказочных героев, этическая оценка их поведения. Анализируя мотивы поведения героини сказки «Морозко», немецкие студенты затрудняются объяснить психологическую основу поступков девушки, которая, замерзая и находясь на грани жизни и смерти, не жалуется, не признается, что ей трудно и плохо, упорно отвечает, что всем довольна. В то же время китайские читатели с сочувствием воспринимают подобное поведение, обусловленное нравственными ценностями, близкими и понятными им. Об этом свидетельствуют эпитеты, которые ки- 
тайцы подбирают для характеристики героини: «терпеливая», «достойная», «скромная». Сопоставление восприятия текста носителями западного и восточного этнопсихолингвистических типов позволяет утверждать, что формирование их социокультурной компетенции происходит в процессе проникновения в ценностный мир русского менталитета [2]. С этой целью инофоны мысленно выделяют систему значимых явлений, постигают жизненные принципы и правила, раскрывают направляющие поступки и цели, определяют присущие русской культуре доминантные ценности и их субординацию с подчиненными ценностями иных уровней культуры. Это позволяет им понять мотивы поведения сказочных героев.

Анализ восприятия фольклорной сказки носителями западной (немецкой) и восточной (китайской) ментальности показывает, что западноевропейский студент воспринимает непременные атрибуты сказочной художественно-образной системы (мотивы превращений, чудес, магических изменений) как алогичные. Передавая сюжет сказки «Царевна-лягушка», немецкие студенты не придают значения эпизоду смерти Кощея Бессмертного, пропускают символические образы дуба, сундука, яйца, иглы и ограничиваются замечанием, что Иван-царевич убил Кощея. Представители восточной культуры, напротив, чувствуют важность отмеченных мотивов, стараются тщательно воспроизвести при пересказе и даже пытаются интерпретировать их символическое значение («яйцо - жизнь», «игла - смерть»). Возможно, это объясняется тем, что в китайской картине мира символ играет очень большую роль. Сопоставительный аспект восприятия сказки позволяет китайцам осмыслить сходство и различия открытых ценностей страны изучаемого языка и родной, установить сходные, отличительные - особенно проти- 
воположные - и нейтральные элементы двух аксиологических сфер.

Особую трудность для восприятия и интерпретации инофонами представляют нравственные проблемы сказок - идея любви к ближнему, покорности воле Божьей, борьбы с грехом, спасения души. Сказка учит не гнаться за «богатством»: «... Пожили месяц, приелось старухе богатое житье, говорит старику: «Хоть живем мы богато, да что в этом толку, коли люди нас не почитают!» [1, с. 23], жить по совести: «... Стал купец помирать (а купчиху-то прежде его на погост свезли) и приказывает: «Дети мои! Живите хорошо - в любви и совете, так, как мы с покойницей жили» [1, с. 76]. Христианское мировоззрение отражается и в особенностях языковой картины мира, которые вербализуются в таком концепте, как «собор»: «Сел он в коляску и поехал в собор. Там уже давно к обедне звонят, и народу привалило видимо-невидимо» [1, с. 87], «Бог - Спаситель»: «Ерш не унывает, на бога уповает...» [1, с. 34].

Помимо этого, русский сказочный дискурс позволяет выделить основные обряды, например, благословение: «...Говорит царю большой сын: «Батюшка, благослови меня, поеду отыскивать матушку...» [1, с. 122], связанное с браком венчание: «...Иван-царевич выбрал Василису Премудрую, тотчас их обвенчали и на радостях пировали целых три дня» [1, с. 137], а также со смертью человека - поминки: «Тут коза с кумою лисою сделали чудесный помин по бирюке: наелись, напились, вышли на двор, коза проводила куму, а сама со своим козленком стала жить да поживать и молочко для козленка добывать» [1, с. 43].

Сюда же можно отнести культурные концепты, характеризующие традиции, уклад и быт деревни, менталитет народа. К особенностям русского национального менталитета Н.О. Лосский относит духовность (свя- 
тость, религиозность), соборность (общинное сознание, единение в духе), всемирную отзывчивость, стремление к высшим формам опыта, широту души, правдоискательство, терпение, власть, славу, совесть [5, с. 81]. В сказках часто упоминается мотив крещения: «Вот родился у дьякона сын. Пришел он мужичка просить кумом быть - захотелось это ему попробовать медку. Ребенка окрестили, мужик кумом стал» [1, с. 142]. Существенная роль принадлежит и концепту кумовства, о котором упоминается даже в сказках о животных: «Лиса с журавлем подружилась, даже покумилась с ним у кого-то на родинах...» [1, с. 169]. Кумовья - крестные родители - рассматриваются как духовные наставники ребенка. Они могут помогать друг другу, совершая добрые дела по велению сердца, а не для того, чтобы получить за них награду, а могут, напротив, преследовать корыстные цели, получая друг от друга какую-либо выгоду. Структурированная интерпретация нравственных проблем, обрядов, культурных концептов русского менталитета помогает иностранной аудитории выделить совпадающие, понятные и принятые ценности как аксиологическую базу предполагаемой коммуникации и обратить внимание на противоположные или уникальные ценности в целях выявления и дальнейшего пояснения при совместных обсуждениях и комментариях.

Следует учитывать и тот факт, что в некоторых персонажах соединяются черты многих других, поэтому их функции в сказках могут быть многолики. Так, Баба-Яга может быть вредителем, который старается погубить героя или героиню («Гуси-лебеди»), похитительницей детей («Сестрица Аленушка и братец Иванушка»), волшебным помощником («Царевна-лягушка»). Поэтому необходимо научить иноязычных студентов оценивать поступки героев сказки и собственные действия с учетом приобретенного опыта. 
Целесообразно остановиться на еще одном персонаже русских сказок - Змее Горыныче, непонятном студентам-инофонам. В русской лингвокультуре Змей Горыныч - летающий многоголовый дракон с тремя, шестью или двенадцатью головами, извергающими огонь. С одной стороны, этот образ мифического существа воплотил в себе все беды, происходившие на Руси, с другой - это сказочный персонаж, некое зло, противопоставленное добру.

В китайской лингвокультуре дракон - символ мира, добра и процветания. Китайцы считают себя продолжателями рода дракона. «Образ дракона - символ императорской власти, поэтому он так широко почитается китайцами и в народе является неотъемлемой частью традиционной народной культуры. В народе образ дракона воплощает дух народа, мечты о будущем и стремление к счастью. Дракон также является символом справедливости, он помогает бедным и слабым» [6, с. 38]. Инофоны должны понять различие в интерпретации этого персонажа в русской и китайской лингвокультуpax, своевременно внести коррективы, определяемые реальным соотношением аксиосфер и конкретной ситуацией. Подобные коррективы позволят понять, что стереотипное представление о сказочных персонажах по-разному отражено в языковом сознании носителей различных культур.

Рассмотрение вышеуказанных аспектов восприятия русской сказки позволяет направлять взаимоотношения иностранной аудитории и представителей страны изучаемого языка в конструктивное русло, преследуя поначалу цель соучастия в решении отдельных локальных задач, а в перспективе - соразвитие как глобальный идеал коммуникации. Адекватное декодирование русской сказки способствует формированию социокультурной компетенции иностранных обучающихся. 
Сказка, воздействуя на инофона, позволяет познать ценности, культуру, составляющие своеобразие менталитета народа страны изучаемого языка, сформировать этико-эстетические жизненные стереотипы иностранных обучающихся, позволяющие достичь взаимопонимания с представителями иноязычной культуры.

\section{Лuтература:}

1. Афанасьев А.Н. Народные русские сказки. М.: Альфа-Книга, 2020. 1087 с.

2. Воробьев В.В. Теоретические и прикладные аспекты лингвокультурологии // Вестник Московского государственного лингвистического университета. 2015. № 13. C. 217-226.

3. Караулов Ю.Н. Русский язык и языковая личность. М.: ЛКИ, 2010. 264 с.

4. Лекторский В.А. Толерантность // Философские науки. 2017. № 3. С. 14-19.

5. Лосский Н.О. Характер русского народа. М.: Ключ, 1990. 98 с.

6. Пропп В.А. Исторические корни русской волшебной сказки. М.: Лабиринт, 2000. $274 \mathrm{c}$.

Lilya Shumskaya,

Ph. D in Philology, Associate Professor of the Department

of language training of Belarussians and other foreign citizens,

Yanka Kupala State University of Grodno (Belarus), akay2012@yandex.ru

\section{Perception of the Russian folk fairy tale in the process of learning Russian as a Foreign Language}

The article examines the collaborative mechanism of different social groups, how the mutual understanding of their cultures causes capacity for cross-cultural communication and forms social and cultural competence in the process of learning Russian as a Foreign Language. The problems of perception and decoding of folklore text are revealed, and the figurative, conceptual, and culturological difficulties arising are analyzed. The differences in the perception and evaluation of culturally significant folklore motifs by the recipients of different mentalities are traced. It is noted that the study of folk tales contributes to the formation of the idea of values, culture, constituting the peculiarity of the mentality of the Russian people.

Keywords: dialogue of cultures; communication; fairy tale; folklore; values; traditions; codevelopment; Russian as a Foreign Language. 